\title{
Magnesium and Mortality in Patients with Diabetes and Early Chronic Kidney Disease
}

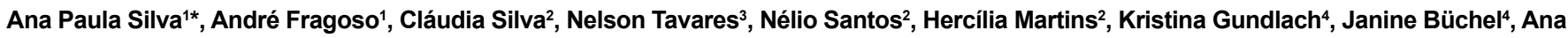
Camacho $^{3}$, Marília Faísca ${ }^{5}$, llídio Jesus Varela ${ }^{3}$ and Pedro Neves ${ }^{1}$

${ }^{1}$ Department of Nephrology, Hospital Faro, Faro, Portugal

2Pathology Clinic, Hospital Faro, Faro, Portugal

${ }^{3}$ Department of Cardiology, Hospital Faro, Faro, Portugal

${ }^{4}$ Fresenius Medical Care Deutschland GmbH, Renal Pharma / Biomedical \& Pharmaceutical Research, Germany

${ }^{5}$ Department of Pharmacology, GnosticLaboratory, Faro, Portugal

\begin{abstract}
Objective: Cardiovascular disease is extensively described as being associated with chronic kidney disease, representing the most important cause of morbidity and mortality in these patients. Recent studies have suggested that hypomagnesaemia may be involved in the pathogenesis of cardiovascular disease in chronic kidney disease patients.
\end{abstract}

Methods: An observational, prospective study involving 191 diabetic patients at chronic kidney disease stages 1-3 divided into groups according to baseline levels of magnesium; $1:<1.2 \mathrm{mg} / \mathrm{dL}, 2: 1.2-2.3 \mathrm{mg} / \mathrm{dL}$ and $3: \geq 2.3$ $\mathrm{mg} / \mathrm{dL}$. Different serum parameters were analyzed and compared between $\mathrm{Mg}$ levels. Carotid eco-Doppler and transthoracic echocardiography were also used to assess calcification features Statistical tests were used to find predictors of cardiovascular mortality, hospitalizations and disease progression.

Results: Patients' survival at 54 months in group 1, 2 and 3 was $27.8 \%, 73.8 \%$ and $80.2 \%$, respectively ( $p<0.001$ ). Magnesium was found to be an independent predictor of both mortality and hospitalizations, with a statistically significant decrease in mortality and hospitalizations observed at higher levels of magnesium. Magnesium levels were also negatively correlated with known cardiovascular risk factors and with serum creatinine. Patients with lower magnesium level were more likely to start a renal replacement therapy.

Conclusions: Lower magnesium levels result in a greater risk of cardiovascular mortality and hospitalization as well as an accelerated progression of renal disease to renal replacement therapy.

Keywords: Magnesium levels; Diabetes; Chronic kidney disease; Cardiovascular disease

\section{Introduction}

In the last few years there has been increasing evidence correlating abnormal serum Mg levels, particularly hypomagnesaemia, with all-cause mortality and different pathological conditions including hypertension, pro-inflammatory states, type 2 diabetes and its complications, and development of atherosclerosis and vascular disease, both in the general population and in patients with chronic kidney disease (CKD) [1-8].

Recent studies have suggested that hypomagnesaemia may be involved in the pathogenesis of CVD in CKD patients and, although the mechanism is still debated, there is growing evidence that lower $\mathrm{Mg}$ levels, shown to be a major risk factor for atherosclerosis, may also favor vascular calcification and development of CVD [9-13].

Previous observational [6,7] and interventional [14,15] clinical studies have already demonstrated that hypomagnesemia is associated with vascular calcification and cardiovascular mortality among patients with end-stage renal disease (ESRD).

Despite the interest in $\mathrm{Mg}$ and in understanding the exact pathophysiologic mechanisms of CVD in CKD, and although Mg has previously been presented as a possible predictor of cardiovascular outcomes in CKD patients [16], there is a scarcity of studies evaluating CVD in earlier stages of renal disease. In addition, there are many variables related to the risk of cardiovascular outcomes and the progression of kidney disease in the diabetic population, and the understanding of how these variables interact and are affected by different $\mathrm{Mg}$ levels still requires further investigation. In the present study we evaluated the association of serum $\mathrm{Mg}$ levels with cardiovascular mortality, hospitalizations, and progression of renal disease in type 2 diabetic patients with mild-moderate CKD.

\section{Subjects and Methods}

An observational, prospective study involving 191 patients was conducted in our outpatient diabetic nephropathy clinic from December 2007 to May 2013.

The study was submitted to and approved by the administration and ethics committee. The study was conducted according to the principles of the Declaration of Helsinki, and study procedures were only performed after signing the informed consent.

*Corresponding author: Ana Paula Silva, Department of Nephrology, Hospital de Faro, Rua Leão Penedo, 8000-386 Faro, Portugal, Tel: +351 2898912 20; Fax: + 3512898912 21; E-mail: anapassionara@gmail.com

Received February 05, 2014; Accepted March 26, 2014; Published March 29 2014

Citation: Silva AP, Fragoso A, Silva C, Tavares N, Santos N, et al. (2014) Magnesium and Mortality in Patients with Diabetes and Early Chronic Kidney Disease. J Diabetes Metab 5: 347. doi:10.4172/2155-6156.1000347

Copyright: (C) 2014 Silva AP, et al. This is an open-access article distributed under the terms of the Creative Commons Attribution License, which permits unrestricted use, distribution, and reproduction in any medium, provided the original author and source are credited. 


\section{Subjects}

Type 2 diabetic patients with a diagnosis of mild-moderate CKD $\left(15 \mathrm{~mL} / \mathrm{min} / 1.73 \mathrm{~m}^{2}<\mathrm{eGFR} \leq 80 \mathrm{~mL} / \mathrm{min} / 1.73 \mathrm{~m}^{2}\right)$ were eligible to participate. The classification of diabetes was based on the guidelines from the American Diabetes Association [17].

The exclusion criteria were previous CVD - defined as a history of one or more of the following: non-fatal myocardial infarction, angina pectoris (stable or unstable), stroke or transient ischemic attacks, peripheral vascular disease or congestive heart failure; uncontrolled hypertension ( $\mathrm{BP} \geq 140 / 90 \mathrm{mmHg}$ ), albumin/creatinine ratio (UACR) $>500$, estimated glomerular filtration rate $(\mathrm{eGFR}) \leq 15 \mathrm{~mL} / \mathrm{min}$ or $>80$ $\mathrm{mL} / \mathrm{min}$, parathyroid hormone $(\mathrm{PTH}) \geq 350 \mathrm{pg} / \mathrm{mL}$, phosphorus $>5.5$, type 1 diabetes, non-diabetic renal disease, neoplasic or infectious diseases. Therapy with thiazide and loop diuretics, spironolactone, $\mathrm{Mg}$ supplements or any laxative or chelate agent containing $\mathrm{Mg}$ was not allowed. Patients with any gastro-intestinal pathology that could possibly interfere with Magnesium absorption were also not included in this study.

All mortalities and hospitalizations motivated by causes other than cardiovascular events were also excluded.

\section{Follow-up}

Patients were recruited on an outpatient nephrology consultation. Patients returned on a regular basis for visits on nephrology consultation 2-3 times a year. Patients with more serious conditions were monitored every 3 months and patients with disease of less concern every 6 months. Patients were continued to be followed in the same institution since in the Algarve region patients with renal disease are referred to Hospital de Faro.

\section{Blood measurements}

Serum samples were collected at baseline in fasting patients and patients were divided according to the $\mathrm{Mg}$ groups. Samples were centrifuged and plasma was frozen at $-80^{\circ} \mathrm{C}$. The option to analyze $\mathrm{Mg}$ levels by groups rather than by a continuous variable was made in order to try to better differentiate the power of lower and higher Mg levels.

$\mathrm{Mg}$ groups were defined as: group 1 with serum $\mathrm{Mg}<1.2 \mathrm{mg} / \mathrm{dL}$, group 2 with $\mathrm{Mg} 1.2-2.3 \mathrm{mg} / \mathrm{dL}$ and group 3 with $\mathrm{Mg} \geq 2.3 \mathrm{mg} / \mathrm{dL}$. The range values for each group resulted from the statistical determination of the 33rd and 66th percentiles of patients' Mg levels.

Several laboratory parameters were analyzed and the results are presented in Table 1. Fibroblast growth factor-23 (FGF-23) serum levels were quantified using an enzyme-linked immunosorbent assay, Human FGF-23 (C-Term) ELISA kit (Cat. \#60-6100 ImmunotopicsInc, San Clemente, CA, USA). Serum levels of 1,25(OH) 23 (vitamin D) were quantified at two time-points (December 2007 and June 2008) with a radioimmunoassay (IDS, Boldon, UK). Vitamin D serum levels for each patient resulted from calculating the mean value of both measurements. The serum levels of cholesterol, HDL, phosphorus, calcium and $\mathrm{Mg}$ were measured using the ARCHITECT c Systems and the AEROSET System (Abbott Diagnostics Division, Abbott Laboratories Abbott Park, IL). LDL cholesterol in human serum was assessed using a MULTIGENT Direct LDL assay (Abbott Diagnostics Division, Abbott laboratories Abbott Park, IL). IL-6 and ox LDL levels were measured using a sandwich enzyme-linked immunoassay (ELISA) kit (eBioscience, San Diego, California). Hemoglobin and PTH levels were measured using a spectrophotometry technique and electro chemiluminescent immunoassay (ECLIA), respectively. PTH

\begin{tabular}{|l|l|}
\hline Characteristics & Values \\
\hline Number of patients enrolled, $\mathrm{n}$ & 191 \\
\hline Age (years) & $62.49 \pm 10.24$ \\
\hline Gender, M/F $(\%)$ & $118 / 73(61.8 / 38.2)$ \\
\hline BMI $\left(\mathrm{kg} / \mathrm{m}^{2}\right)$ & $26.1 \pm 4.7$ \\
\hline Hb $(\mathrm{g} / \mathrm{dL})$ & $12.5 \pm 1.9$ \\
\hline Albumin $(\mathrm{g} / \mathrm{dL})$ & $4.1 \pm 0.6$ \\
\hline Total cholesterol $(\mathrm{mg} / \mathrm{dL})$ & $190.2 \pm 39.1$ \\
\hline HDL $(\mathrm{mg} / \mathrm{dL})$ & $50.8 \pm 21.2$ \\
\hline LDL $(\mathrm{mg} / \mathrm{dL})$ & $111.2 \pm 29.9$ \\
\hline Creatinine $(\mathrm{mg} / \mathrm{dL})$ & $2.0 \pm 1.0$ \\
\hline eGFR $(\mathrm{mL} / \mathrm{min})$ & $41.6 \pm 23.2$ \\
\hline Albumin/creatinine ratio $\left(\mu \mathrm{gg} / \mathrm{mg}^{2}\right)$ & $245.1 \pm 114.8$ \\
\hline Phosphorus $(\mathrm{mg} / \mathrm{dL})$ & $4.4 \pm 1.3$ \\
\hline PTH $(\mathrm{pg} / \mathrm{mL})$ & $141.1 \pm 111.5$ \\
\hline Calcium $(\mathrm{mg} / \mathrm{dL})$ & $9.4 \pm 0.8$ \\
\hline Calcium x Phosphorus $\left(\mathrm{mg} / \mathrm{dL}^{2}\right)$ & $41.3 \pm 11.7$ \\
\hline FGF-23 $(\mathrm{RU} / \mathrm{mL})$ & $192.7 \pm 208.5$ \\
\hline$\left[1,25(\mathrm{OH}){ }_{2} \mathrm{D} 3\right](\mathrm{pg} / \mathrm{mL})$ & $19 \pm 8.1$ \\
\hline HOMA-IR & $2.2 \pm 1.8$ \\
\hline IL-6 $(\mathrm{pg} / \mathrm{mL})$ & $2.3 \pm 0.8$ \\
\hline OxLDL $(\mathrm{U} / \mathrm{L})$ & $46.9 \pm 23.2$ \\
\hline PP $(\mathrm{mmHg})$ & $53.7 \pm 19.1$ \\
\hline LVMI $\left(\mathrm{g} / \mathrm{m}^{2}\right)$ & $106.3 \pm 26.1$ \\
\hline IMT $(\mathrm{mm})$ & $1.0 \pm 0.2$ \\
\hline Hospitalization days & $7.3 \pm 12.3$ \\
\hline & \\
\hline
\end{tabular}

Table 1: Patients' baseline characteristics.

concentrations were measured on an Immulite 2000 Intact PTH assay (Cat. \#L2KPP2, Siemens Medical Solutions Diagnostics, Los Angeles, CA, USA).

The degree of insulin resistance was estimated using the homeostasis model assessment (HOMA-IR) described by Matthews et al. [18].

Serum creatinine was measured by the enzymatic method, using the ARCHITECT $^{\oplus}$ device (Abbott Diagnostics Division, Abbott Laboratories Abbott Park, IL). GFR was estimated using a formula derived by the Modification of Diet in Renal Disease study group [19].

\section{Echocardiography}

Transthoracic echocardiography was performed using a General Electrical Medical Systems echograph, model Vivid 7 with a probe (GE Healthcare, Wisconsin, USA). Carotid eco-Doppler was performed using a General Electrical Medical Systems echograph, model Vivid 4 with a linear probe of $10 \mathrm{MHz}$ (GE Healthcare, Wisconsin, USA). For the assessment of the carotid artery intima-media thickness (IMT), the protocol of the American Society of Echocardiography was followed. Left ventricular mass index (LVMI) was calculated by applying the regression equation from Penn convention [20].

\section{Outcomes}

The primary outcome of this study was cardiovascular mortality. Deaths were confirmed by review of autopsy reports, death certificates, medical records or information obtained from next of kin or family members and classified as cardiovascular or non-cardiovascular death. Cardiovascular deaths were defined as mortality caused by coronary heart disease, heart failure, peripheral vascular disease and cerebrovascular disease.

Secondary outcomes comprised hospitalization due to 
cardiovascular causes, and progression of renal disease. The evaluation and characterization of hospitalizations were based on hospital admission clinical record and were also classified as due to cardiovascular or non-cardiovascular causes. Hospitalization days due to cardiovascular causes met the same criteria for cardiovascular deaths but with no mortality. Progression of renal failure was assessed on follow-up consultations by analytical evaluations of renal function. Patients with an eGFR $<10 \mathrm{~mL} / \mathrm{min}$ started a renal replacement therapy (RRT), hemodialysis or peritoneal dialysis according to the patient's choice. In addition, and despite not being a main objective of our study, we also assessed any possible relationship between $\mathrm{Mg}$ and renal disease and other variables such as FGF-23, a recently identified hormone involved in mineral homeostasis and presumably associated with CKD pathophysiology.

\section{Statistical analysis}

We used descriptive statistics. For comparisons between groups we used the ANOVA test with Scheffé post-hoc. The Kaplan-Meier method for measuring patient survival was applied and a comparison between the three groups was based on the log rank test. The risk factors and their hazard ratio (HR) were calculated using a Cox regression for mortality and a multivariate logistic regression for hospitalization. All variables were added to the models as continuous variables, with exception of age, gender and $\mathrm{Mg}$ levels that were categorized. Simple linear regressions were used to investigate any possible correlation between $\mathrm{Mg}$ and renal disease and between $\mathrm{Mg}$ and cardiovascular risk factors. Differences were considered statistically significant for $p$-values $<0.05$. Statistical analyses were performed using the SPSS program, v17.0.

\section{Results}

A total of 191 patients were evaluated during 65 months, from December 2007 to May 2013. The mean age was $62.67 \pm 10.95$ years (4287 ) and $38.2 \%$ (73) of them were female (Table 1). The mean follow-up time was $45.7 \pm 15.3$ months (8-65).

Patients were allocated into groups according to their serum $\mathrm{Mg}$ values. Group 1 encompassed 63 patients, and both groups 2 and 3 included 64 patients (Table 2).

Patients with serum $\mathrm{Mg}$ levels $\geq 2.3 \mathrm{mg} / \mathrm{dL}$ had significant higher levels of vitamin $\mathrm{D}, \mathrm{Hb}$, albumin and a greater eGFR, as well as significant lower values of creatinine, phosphorus, PTH, FGF-23, HOMA-IR, IL-6, oxLDL, LVMI, PP, IMT and less hospitalization days.

Using the Kaplan-Meier analysis, it was observed that patients' survival at 54 months was $27.8 \%$ in group 1, $73.8 \%$ in group 2 and 80.2 $\%$ in group 3 . In addition, the risk of cardiovascular death significantly decreased with higher levels of $\mathrm{Mg}$ ( $\log$ rank=15.93; $\mathrm{p}<0.001$ ) (Figure 1). Using a multivariate Cox regression, age $\mathrm{HR}=1.607$ (1.078-2.396), serum Mg levels 0.06 (0.282-0.875), FGF-23 1.005 (1.001-1,10), phosphorus 1.156 (1.010-1.768), Hb 0.474 (0.204-0.981), ox LDL 1.047 (1.001-1.118) and IMT 1.017 (1.078-2.396) were found to independently predict patient survival $(\mathrm{p}<0.05)$ in opposition to the other variables (Figure 2). The mortality decreased at normomagnesemic levels compared to low Mg levels. A further statistically significant decrease in mortality was observed with $\mathrm{Mg} \geq 2.3 \mathrm{mg} / \mathrm{dL}$ (Figure 1).

Regarding cardiovascular hospitalization, patients in group 1 presented a greater mean length $[12.4 \pm 8.7$ days (1-34)] when compared with patients in group $2[10.2 \pm 16.5(0-79)]$ and group $3[1.8$ $\pm 6.8(0-34)]$. These differences were statistically significant $(\mathrm{p}<0.001)$.

\begin{tabular}{|c|c|c|c|c|}
\hline & $\begin{array}{l}\text { Group } 1 \\
<1.2 \mathrm{mg} / \mathrm{dL} \\
n=63\end{array}$ & $\begin{array}{l}\text { Group } 2 \\
1.2-2.3 \mathrm{mg} / \\
\mathrm{dL} n=64\end{array}$ & $\begin{array}{l}\text { Group } 3 \\
\geq 2.3 \mathrm{mg} / \mathrm{dL} \\
n=64\end{array}$ & $p$ - Value \\
\hline Age (years) & $67.8 \pm 9.1$ & $62.2 \pm 9.4$ & $59.3 \pm 10.2^{a, b}$ & $<0.001$ \\
\hline BMI $\left(\mathrm{kg} / \mathrm{m}^{2}\right)$ & $24.3 \pm 2.2$ & $27.1 \pm 6.0$ & $26.2 \pm 4.2^{\mathrm{a}}$ & 0.007 \\
\hline $\mathrm{Hb}(\mathrm{g} / \mathrm{dL})$ & $12.0 \pm 1.8$ & $12.6 \pm 1.8$ & $12.9 \pm 2.0^{a}$ & 0.041 \\
\hline Albumin (g/dL) & $3.8 \pm 0.6$ & $4.2 \pm 0.7^{a}$ & $4.3 \pm 0.4^{a}$ & $<0.001$ \\
\hline $\begin{array}{l}\text { Total Cholesterol } \\
(\mathrm{mg} / \mathrm{dL})\end{array}$ & $191.7 \pm 44.7$ & $188.3 \pm 32.9$ & $190.9 \pm 40.5$ & 0.881 \\
\hline Creatinine (mg/dL) & $2.6 \pm 0.9$ & $2.0 \pm 0.9^{a}$ & $1.7 \pm 0.9^{a}$ & $<0.001$ \\
\hline eGFR (mL/min) & $25.5 \pm 12.2$ & $41.3 \pm 22.0^{a}$ & $51.8 \pm 23.8^{a, b}$ & $<0.001$ \\
\hline Phosphorus (mg/dL) & $5.5 \pm 1.6$ & $4.4 \pm 0.8^{a}$ & $3.7 \pm 0.7^{\mathrm{a}, \mathrm{b}}$ & $<0.001$ \\
\hline PTH $(p g / m L)$ & $257.3 \pm 127.0$ & $141.8 \pm 83.5^{a}$ & $69.1 \pm 36.8^{\mathrm{a}, \mathrm{b}}$ & $<0.001$ \\
\hline Calcium (mg/dL) & $9.4 \pm 0.8$ & $9.5 \pm 0.9$ & $9.4 \pm 0.8$ & 0.853 \\
\hline FGF-23 (RU/mL) & $484.1 \pm 208.9$ & $142.4 \pm 87.6^{a}$ & $55.3 \pm 11.2^{a, b}$ & $<0.001$ \\
\hline $1,25(\mathrm{OH})_{2} \mathrm{D} 3(\mathrm{pg} / \mathrm{mL})$ & $9.5 \pm 1.8$ & $17.6 \pm 7^{a}$ & $26.2 \pm 3.4^{a, b}$ & $<0.001$ \\
\hline HOMA-IR & $3.7 \pm 0.9$ & $2.7 \pm 1.9^{a}$ & $0.9 \pm 1.0^{\mathrm{a}, \mathrm{b}}$ & $<0.001$ \\
\hline IL-6 (pg/mL) & $2.8 \pm 0.4$ & $2.6 \pm 0.7$ & $1.7 \pm 0.7^{\mathrm{a}, \mathrm{b}}$ & $<0.001$ \\
\hline OxLDL (U/L) & $76.6 \pm 14.2$ & $47.9 \pm 17.4^{\mathrm{a}}$ & $27.7 \pm 5.4^{\mathrm{a}, \mathrm{b}}$ & $<0.001$ \\
\hline $\mathrm{PP}(\mathrm{mmHg})$ & $74.3 \pm 12.1$ & $47.6 \pm 5.3$ & $38.0 \pm 9.6^{a, b}$ & 0.002 \\
\hline LVMI $\left(\mathrm{g} / \mathrm{m}^{2}\right)$ & $133.2 \pm 18.4$ & $109.5 \pm 23.0^{\mathrm{a}}$ & $86.9 \pm 13.8^{a, b}$ & $<0.001$ \\
\hline IMT & $1.2 \pm 0.2$ & $1.03 \pm 0.2$ & $0.79 \pm 0.7^{a, b}$ & $<0.001$ \\
\hline Hospitalization days & $12.4 \pm 8.7$ & $10.2 \pm 16.5$ & $1.8 \pm 6.8^{\mathrm{a}, \mathrm{b}}$ & $<0.001$ \\
\hline
\end{tabular}

Results of post-hoc analysis: ${ }^{a} p<0.05$ vs. Group $1,{ }^{b} p<0.05$ vs. Group 2 Table 2: Comparison of variables among the $3 \mathrm{Mg}$ groups.

Survival Functions

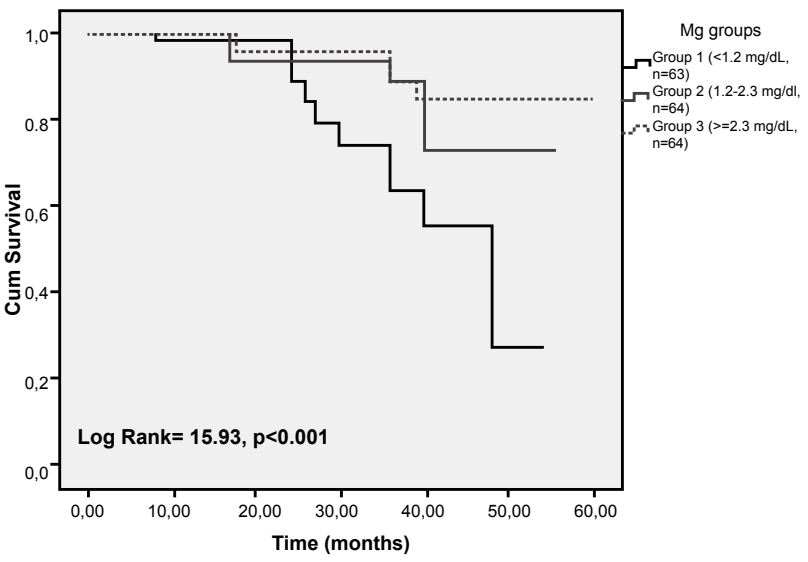

Figure 1: Kaplan-Meier survival curve by group of $\mathrm{Mg}$.

Applying a multivariate logistic regression, $\mathrm{Mg}$ OR=0.209 (0.44-0.998), FGF-23 1.027 (0.959-1.099), phosphorus 1.008 (0.957-1.176), ox LDL 1.060 (1.010-1.113), Hb 0.596 (0.263-0.859) and PP 1.052 (1.001-1.106) were found to predict the need of hospitalization $(\mathrm{p}<0.05)$ in opposition to the other assessed variables ( $>0.05)$ (Figure 3). A statistically significant decrease in the risk of hospitalization was observed with $\mathrm{Mg}$ levels $\geq 2.3 \mathrm{mg} / \mathrm{dL}$ (Figure 4).

To evaluate possible causes of the mortality and hospitalization differences, simple linear regressions of $\mathrm{Mg}$ with several factors was assessed. $\mathrm{Mg}$ levels were found to be negatively correlated with creatinine $(\mathrm{R}=-0.346, \mathrm{p}<0.0001)$, albumin creatinine ratio $(\mathrm{R}=-0.351$, $\mathrm{p}<0.001)$, Calcium $(\mathrm{R}=-0.034, \mathrm{p}=0.641)$, Phosphorus $(\mathrm{R}=-0.562, \mathrm{p}<$ $0.001)$, PTH $(\mathrm{R}=-0.710, \mathrm{p}<0.001)$, Il-6 $(\mathrm{R}=-0.666, \mathrm{p}<0.001)$, FGF-23 $(\mathrm{R}=-0.798, \mathrm{p}<0.001)$, IMT $(\mathrm{R}=-0.747, \mathrm{p}<0.001)$, LVMI $(\mathrm{R}=-0.783, \mathrm{p}<$ 


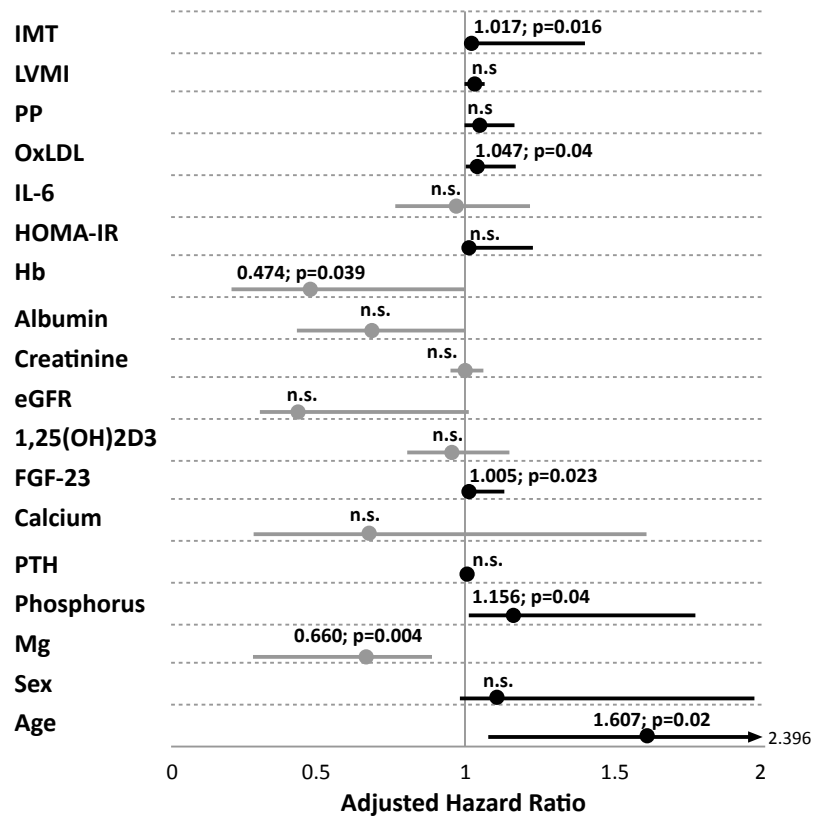

Figure 2: Multivariate Cox regression analysis for cardiovascular mortality.

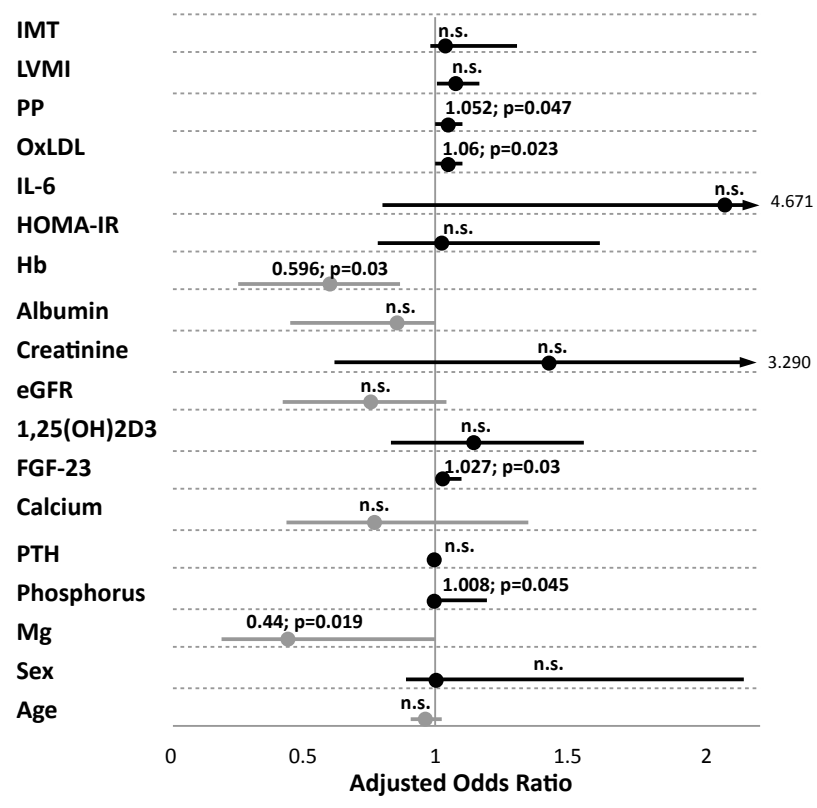

Figure 3: Multivariate logistic regression analysis for cardiovascular hospitalizations.

$0.001)$ and $\mathrm{PP}(\mathrm{R}=-0.780, \mathrm{p}<0.001)$, while it was positively correlated with albumin $(\mathrm{R}=0.327, \mathrm{p}<0.001)$ and vitamin $\mathrm{D}(\mathrm{R}=0.840, \mathrm{p}<0.001)$.

Finally, it was observed that age $\mathrm{OR}=1.093$ (1.049-1.781), ox LDL 1.116 (1.008-2.058), serum Mg 0.477 (0.233-0.901) and creatinine 2.840 (1.182-6.823) were independent predictors of patients' renal disease progression to RRT $(\mathrm{p}<0.05)$. There was also a statistically significant decrease in the risk of progression to RRT with $\mathrm{Mg}$ levels $>2.3 \mathrm{mg} / \mathrm{dL}$ (Figure 4).

\section{Discussion}

In this study we evaluated the association of Mg levels with mortality and hospitalization, as well as the relationship of $\mathrm{Mg}$ with progression or renal disease in type 2 diabetic patients with mild-moderate CKD.

The allocation of patients according to their Mg levels in tertiles resulted in a noteworthy distribution. As normal $\mathrm{Mg}$ serum levels are defined as $1.6-2.5 \mathrm{mg} / \mathrm{dL}$ [21], the group allocation roughly divided the patients in hypo-, normal- and hypermagnesaemic. The mortality results revealed significant differences between groups. In this study, patients with higher $\mathrm{Mg}$ levels have better survival rates than patients with lower levels. In addition $\mathrm{Mg}$ was found to independently predict patient survival, with a decreased risk of cardiovascular mortality associated with higher Mg levels. Since all three groups presented well-known cardiovascular risk factors, the attempt to identify a single factor responsible for the cardiovascular mortality results is probably not reasonable as it would not reflect the multifactorial nature of the disease. It is our understanding that these results might be explained by an overall disturbance of the mineral metabolism that manifests in an increased production of activating factors (e.g. phosphorus, calcium) and a decreased production of protective factors such as $\mathrm{Mg}$.

The results of survival functions demonstrated that lower $\mathrm{Mg}$ levels are predictive of cardiovascular mortality in type 2 diabetics with mild-moderate CKD. Of course it is of notice that several parameters differ between groups. Most strikingly, the eGFR is lower in patients with lower $\mathrm{Mg}$, which indicates a more severe chronic renal failure. Therefore the higher mortality could be due to a progress in disease. However, by calculating multivariate Cox regression, eGFR does not come up as an independent risk factor, whereas $\mathrm{Mg}$ does and with the lowest p-value. So it seems reasonable to draw conclusions regarding $\mathrm{Mg}$ and its association with mortality. To the best of our knowledge, this association has only been previously demonstrated for advanced stages of renal disease, in patients already requiring maintenance hemodialysis [3,7]. On the other side, studies examining Mg levels in diabetic patients without known CKD exist. These studies show that hypomagnesemia is a common problem in diabetics and suggest this to

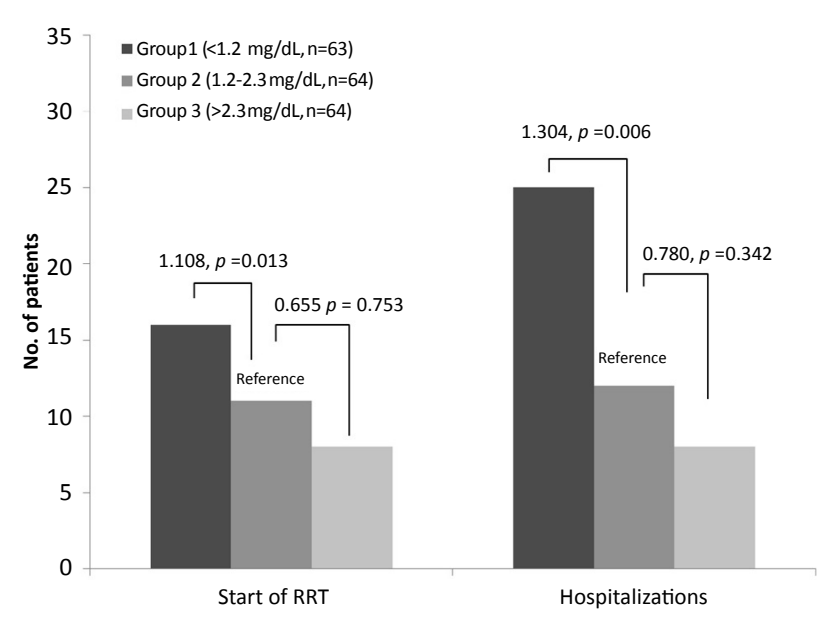

Figure 4: Alignment of hospitalizations and start of RRT with Mg groups Numbers above bars represent the Cox regression results (hazard ratios) for start of RRT and logistic regression results (odds ratios) for hospitalizations. 
be a risk factor for renal deterioration [5,22]. Thus, our results fill this gap and raise interest for further analysis assessing the important role of $\mathrm{Mg}$ as a possible marker/predictor of cardiovascular mortality in the entire diabetic population.

Similar results were obtained for cardiovascular hospitalization and progression of renal disease. $\mathrm{Mg}$ was found to be a predictive variable for the need of cardiovascular hospitalization and for progression of renal disease to RRT, where lower levels were associated with an increased risk.

We also approached the association of Mg levels with other wellknown factors of cardiovascular risk and renal disease. Our results suggested that $\mathrm{Mg}$ levels were inversely correlated with phosphorus, LVMI, IMT and PP, as well as with creatinine, an established marker for the assessment of renal function. Taking it all together, it seems that as $\mathrm{Mg}$ increases, renal function improves and cardiovascular risk decreased.

These data seem to be in accordance with previously reported in vitro and clinical studies that have already correlated lower Mg levels with vascular calcification [13,23,24], and cardiovascular mortality [25] in hemodialysis patients and also with progression to ESRD [22] as well as data from animal [26] and in vitro [27-29] studies stating that increased $\mathrm{Mg}$ levels protect against vascular calcification.

In addition, FGF-23 was also found to be an independent predictor of cardiovascular mortality and need of hospitalization for these patients. We were not able to find in the literature any manuscript evaluating the correlation between FGF-23 and Mg levels and cardiovascular mortality in this population. Thus, we believe these data can be a starting point for future and more robust studies to ascertain the real relationship between FGF-23 and diabetes as well as their implications on mortality and morbidity on patients with mild to moderate chronic kidney disease. When interpreting all the results together it seems plausible to assume that $\mathrm{Mg}$ exerts both cardio- and renoprotective roles. Thus, $\mathrm{Mg}$ levels might have a significant clinical relevance as a marker/predictor of cardiovascular mortality and need for hospitalization, and not least, a therapeutic role for $\mathrm{Mg}$, especially in CKD patients with cardiovascular disease, should be considered.

The main limitations of this manuscript are the relatively small sample size and the limited statistical power of these analyses. However, these are preliminary results of a long-term project and already present new important insights regarding the association of $\mathrm{Mg}$ and cardiovascular mortality, as we believe this is the first time $\mathrm{Mg}$ is presented as a predictor of mortality and need of hospitalization in diabetic patients with mild-moderate CKD.

Nevertheless, we believe interventional, prospective studies with a big sample size and robust statistical analysis are required in order to confirm these associations and to reinforce the cardio and renoprotective roles of $\mathrm{Mg}$ especially in earlier stages of renal disease. Further, additional studies should assess a possible benefit of $\mathrm{Mg}$ supplementation as well as the mechanism behind it.

This study, and similarly to other independent studies conducted by the authors [30,31], bring new input to the diversified puzzle of upcoming variables other than traditional and non-traditional cardiovascular risk factors, that can possibly be translated and clinically used as predictors of mortality in earlier stages of CKD.

In conclusion, our results suggest that $\mathrm{Mg}$ is a predictor of cardiovascular mortality and hospitalization in type 2 diabetic patients with CKD. Furthermore, lower serum Mg levels result in a greater risk of cardiovascular mortality and hospitalization as well as an accelerated progression of renal disease to RRT.

\section{Disclosures}

KG and JB are current employees of Fresenius Medical Care Deutschland $\mathrm{GmbH}$. The remaining authors have no relevant conflict of interests to declare.

\section{Acknowledgment}

All authors of this research paper have directly participated in the planning, execution, or analysis of this study.

\section{References}

1. Malpuech Brugère C, Nowacki W, Daveau M, Gueux E, Linard C, et al. (2000) Inflammatory response following acute magnesium deficiency in the rat. Biochim Biophys Acta 1501: 91-98.

2. Mather HM, Nisbet JA, Burton GH, Poston GJ, Bland JM, et al. (1979) Hypomagnesaemia in diabetes. Clin Chim Acta 95: 235-242.

3. Ishimura E, Okuno S, Yamakawa T, Inaba M, Nishizawa Y (2007) Serum magnesium concentration is a significant predictor of mortality in maintenance hemodialysis patients. Magnes Res 20: 237-244

4. Reffelmann T, Ittermann T, Dörr M, Völzke H, Reinthaler M, et al. (2011) Low serum magnesium concentrations predict cardiovascular and all-cause mortality. Atherosclerosis 219: 280-284

5. Pham PC, Pham PM, Pham SV, Miller JM, Pham PT (2007) Hypomagnesemia in patients with type 2 diabetes. Clin J Am Soc Nephrol 2: 366-373.

6. Van Laecke S, Nagler EV, Verbeke F, Van Biesen W, Vanholder R (2013) Hypomagnesemia and the risk of death and GFR decline in chronic kidney disease. Am J Med 126: 825-831.

7. Sakaguchi Y, Fujii N, Shoji T, Hayashi T, Rakugi H, et al. (2014) Hypomagnesemia is a significant predictor of cardiovascular and non-cardiovascular mortality in patients undergoing hemodialysis. Kidney Int 85: 174-181.

8. Ozgür Keşkek S, Kırım S, Karaca A, Saler T (2013) Low serum magnesium levels and diabetic foot ulcers. Pak J Med Sci 29: 1329-1333.

9. Spiegel DM (2011) Magnesium in chronic kidney disease: unanswered questions. Blood Purif 31: 172-176.

10. Covic AC (2010) Magnesium in chronic kidney disease - More than just phosphate binding. Europ Nephrol 4.

11. Kanbay M, Goldsmith D, Uyar ME, Turgut F, Covic A (2010) Magnesium in chronic kidney disease: challenges and opportunities. Blood Purif 29: 280-292.

12. Massy ZA, Drueke TB (2010) Magnesium and outcomes in patients with chronic kidney disease: focus on vascular calcification, atherosclerosis and survival. Clin Kidney J 5: i52-i61.

13. Ishimura E, Okuno S, Kitatani K, Tsuchida T, Yamakawa T, et al. (2007) Significant association between the presence of peripheral vascular calcification and lowe serum magnesium in hemodialysis patients. Clin Nephrol 68: 222-227.

14. Turgut F, Kanbay M, Metin MR, Uz E, Akcay A, et al. (2008) Magnesium supplementation helps to improve carotid intima media thickness in patients on hemodialysis. International Urology and Nephrology 40: 1075-1082.

15. Tzanakis IP, Oreopoulos DG (2009) Beneficial effects of magnesium in chronic renal failure: a foe no longer. Int Urol Nephrol 41: 363-371.

16. Kanbay M, Yilmaz MI, Apetrii M, Saglam M, Yaman H, et al. (2012) Relationship between serum magnesium levels and cardiovascular events in chronic kidney disease patients. Am J Nephrol 36: 228-237.

17. American Diabetes Association (2010) Diagnosis and classification of Diabetes Mellitus. Diabetes Care 33: S62-S69.

18. Matthews DR, Hosker JP, Rudenski AS, Naylor BA, Treacher DF, et al. (1985) Homeostasis model assessment: insulin resistance and beta-cell function from fasting plasma glucose and insulin concentrations in man. Diabetologia 28 : 412-419.

19. Levey AS, Bosch JP, Lewis JB, Greene T, Rogers N, et al. (1999) A more accurate method to estimate glomerular filtration rate from serum creatinine: a new prediction equation. Modification of Diet in Renal Disease Study Group. 
Citation: Silva AP, Fragoso A, Silva C, Tavares N, Santos N, et al. (2014) Magnesium and Mortality in Patients with Diabetes and Early Chronic Kidney Disease. J Diabetes Metab 5: 347. doi:10.4172/2155-6156.1000347

Ann Intern Med 130: 461-470.

20. Devereux RB, Reichek N (1977) Echocardiographic determination of left ventricular mass in man. Anatomic validation of the method. Circulation 55: 613-618

21. Tietz NW (1990) Clinical Guide to Laboratory Tests (2ndedn), Philadelphia, PA WB Saunders.

22. Sakaguchi Y, Shoji T, Hayashi T, Suzuki A, Shimizu M, et al. (2012) Hypomagnesemia in type 2 diabetic nephropathy: a novel predictor of endstage renal disease. Diabetes Care 35: 1591-1597.

23. Wei M, Esbaei K, Bargman J, Oreopoulos DG (2006) Relationship between serum magnesium, parathyroid hormone, and vascular calcification in patients on dialysis: a literature review. Perit Dial Int 26: 366-373.

24. Okasha K, El Berndary A, Mourad A (2010) Evaluation of peripheral vascular calcification and serum magnesium level in a group of egyptian hemodialysis patients. Arab J Nephrol Transplant 3: 11-16.

25. Nassiri AA, Hakemi MS (2013) Serum magnesium level and cardiovascular disease in dialysis patients. Iran J Kidney Dis 7: 2-4.
26. De Schutter TM, Behets GJ, Geryl H, Peter ME, Steppan S, et al. (2013) Effect of a magnesium-based phosphate binder on medial calcification in a rat mode of uremia. Kidney Int 83: 1109-1117.

27. Kircelli F, Peter ME, Sevinc Ok E, Celenk FG, Yilmaz M, et al. (2012) Magnesium reduces calcification in bovine vascular smooth muscle cells in a dose-dependent manner. Nephrol Dial Transplant 27: 514-521.

28. Louvet L, Büchel J, Steppan S, Passlick-Deetjen J, Massy ZA (2013) Magnesium prevents phosphate-induced calcification in human aortic vascula smooth muscle cells. Nephrology Dialysis Transplantation 28: 869-878.

29. Salem S, Bruck H, Bahlmann FH, Peter M, Passlick-Deetjen J, et al. (2012) Relationship between magnesium and clinical biomarkers on inhibition of vascular calcification. Am J Nephrol 35: 31-39.

30. Silva AP, Fragoso A, Pinho A, Tavares N, Camacho A, et al. (2013) Phosphorus as an early marker of morbidity and mortality in type 2 chronic kidney disease diabetic patients. J Diabetes Complications 27: 328-332.

31. Silva AP, Fragoso A, Silva C, Viegas C, Tavares N, et al. (2013) What is the role of apelin regarding cardiovascular risk and progression of renal disease in type 2 diabetic patients with diabetic nephropathy? Biomed Res Int 2013: 247649.
This article was originally published in a special issue, Diabetic Cardiovascular Complications handled by Editor(s). Dr. Zhengyuan Xia, University of Hong Kong, Hong Kong 